\title{
Performance of a new desiccant bed using phase change material
}

\author{
Boutheina Zallama*, Leila Zili Ghedira, Sassi Ben Nasrallah \\ Université de Monastir, École Nationale d'Ingénieurs de Monastir, Laboratoire LESTE, \\ Avenue Ibn El Jazzar 5000, Monastir, Tunisie
}

\begin{abstract}
The main objective of this study was to conduct an experimental analysis to investigate the performance of a new desiccant bed. Therefore, tests were carried out in a desiccator filled with a porous media, i.e. silica gel used as desiccant enhanced with phase change material, using variable inlet climate conditions. Experimental tests were performed to assess the effect of the new packed bed on the adsorption capacity and this by evaluating the outlet evolutions of temperature, relative humidity and absolute humidity. The experimental setup used in this study is a blower enabling to adjust the flow rate, temperature and relative humidity. The amount of adsorbed mass of moisture is also measured and discussed.
\end{abstract}

\section{Introduction}

The interest of our project is due to its environmental impact and due to its diverse practical applications of science and engineering such as: thermal management of electronic cooling; improving the performance of thermal transfer systems; optimization of desiccant beds and heat storage beds.

Many efforts were carried out to replace chlorofluorocarbons (CFC) and hydrochlorofluorocarbons (HCFC) used in traditional compression refrigeration in order to reduce the amount of energy used for domestic heating and cooling applications [1]. Literature is rich, and various reviews concerning this topic are available. For instance, an interesting review on desiccant cooling systems was reported in [2, 3] and details about the adsorption process could be found in $[4,5]$. Various studies used the solar integrated design for regenerating the desiccant [68]. Mutsuhiro et al. [9] have proposed and studied experimentally a new type of Humidity Swing Airconditioning system (HSA) consisting of a desorption cooling system in the adsorbate instead of a cooling system by water spraying. Packed bed systems [10] can be used in adsorption of water vapor, organic solvent and some toxic gases. For a specific adsorbed substance an adequate adsorbent needs to be selected. For example, active carbon is usually used for adsorption of oil or organic solvent. Silica gel and molecular sieves are used for adsorption of water vapor. Thus, the desorption cooling performance in silica gel was discussed within packed beds. In fact, a packed-bed system usually consists of two columns which are filled with an adsorbent. The two columns are arranged in a periodicswitched operation. While one is for adsorption, the other is for desorption. In order to proceed a cyclic operation, an input heat is required for the regeneration of the adsorbent in the desorption process.

Recently investigations have focused on the optimization of desiccant cooling systems by introducing phase change material in the desiccant bed which will be presented in this study using paraffin as phase change material.

\section{Experimental setup}

Equations should be centred and should be numbered with the number on the right-hand side. We conceived and realized, within our research laboratory LESTE, a climatic wind tunnel intended for the study of desiccators with adjusted air temperature and moisture by means of a conditioning enclosure. Air flow rate is controlled with an air flow regulator designed to maintain a constant flow through the system. This installation has the advantage of ensuring air circulation, in a closed buckle, with well controlled dynamic and hygrothermic characteristics. For this study, we use silica gel as adsorbent. Silica gel is, in fact, a porous material with a high adsorbing water vapor capacity. Consequently, it is used as desiccant in various applications.

The experimental system for investigation of heat and mass transfer in a desiccator filled with silica gel is shown in Figure 1.

Photographs of the wind tunnel and the airconditioning enclosure are presented in Figures 2 and 3 below.

\footnotetext{
* Corresponding author: zallama.boutheina@live.fr
} 


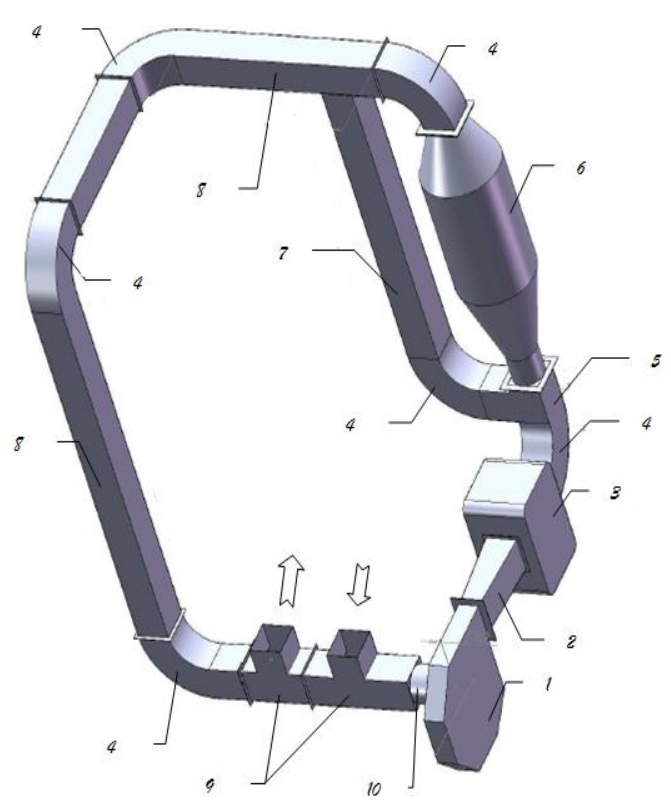

Fig. 1. Different elements of the climatic wind tunnel.

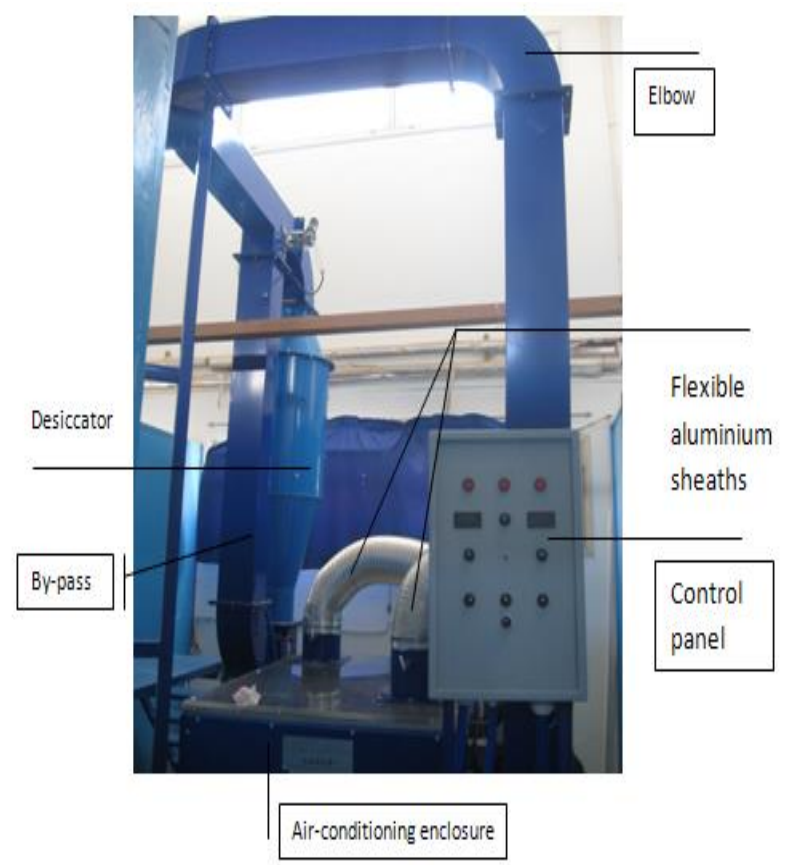

Fig. 2. Photography of the experimental setup.

In order to control air moisture and temperature, we designed an insulated air-conditioning enclosure. The air-conditioning enclosure role is detailed as following:

Air humidity is fixed indirectly by imposing dry bulb temperature and dew point temperature.

Dry temperature is achieved by means of heating resistances with fins, when required temperature is over atmospheric one, and a heat exchanger connected to a cryostat in the opposite case.

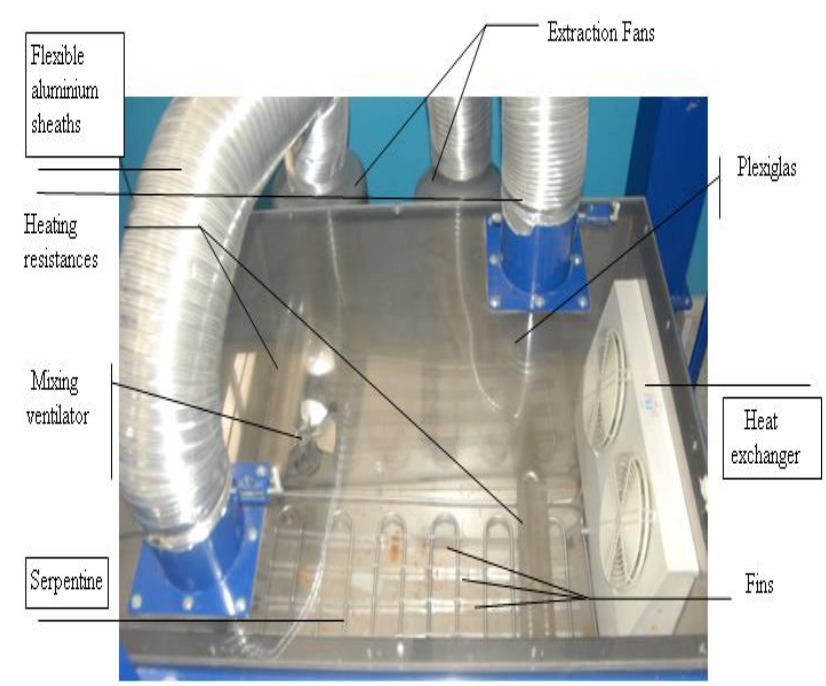

Fig. 3. Air conditioning enclosure.

Dew point temperature is the imposed one on a thin water layer in the bottom of the enclosure using a serpentine related to a cryostat.

The enclosure is, in fact, provided with two heating resistances connected to a thermo-regulator, a heat exchanger commanded by a cryostat serving to fix the dry air temperature when desired value is under ambient one, two air mixing ventilators and a second heat exchanger, that is to say a copper serpentine, immersed in a low water thickness and which is also controlled by a cryostat fixing so, the dew point temperature. The dew point temperature is, thus, selected according to the desired relative humidity while knowing the dry temperature and referring to the psychrometric diagram. We ensure, then, the moisture and temperature air control by the conditioning enclosure.

Let us note that the wind tunnel is equipped with a by-pass which is used for the establishment of the required conditioning before the launching of the experiments. Once the imposed temperature, moisture and air flow rate are stabilized, the air is supplied to the desiccator. Our installation allows us to use various reactors with different diameters. We currently have three desiccators at 20,30 and $50 \mathrm{~cm}$ diameters.

A control panel and an electrical equipment box are used to ensure the ordering of the system. The desk includes all the control knobs. In fact, it ensures the order, the visualization and the adjustment of the various existing elements. The electrical equipment box feeds all the blower elements in electricity and is provided with the air flow regulator.

The experiences are led on a silica gel packed bed. We have, then, utilized reliable sensors, i. e. thermohygrometers which measure the following parameters : relative humidity $\mathrm{Hr}$, absolute humidity Habs, dew point temperature $\mathrm{Td}$, dry bulb temperature $\mathrm{T}$, wet bulb temeprature Tw, PT100 temperature integrated in the probe and thus to exploit the experimental measurements.

The silica gel is initially regenerated by means of electric oven for $5 \mathrm{~h}$ at $70^{\circ} \mathrm{C}$. Then, once the steady state of inlet air conditions is established, we start the 
adsorption mechanism for a pure silica gel bed. Then, tests were carried out to assess the influence of introducing PCM on silica gel packed bed on the bed performance.

\section{Results and discussions}

As it can be seen from the Table 1 and Fig. 4, the measurements are carried out at nearly constant conditions of process air (speed, temperature and humidity at the bed entrance).

The adsorption mechanism is studied for the fixed inlet air conditions that are:

$$
\begin{aligned}
& -\mathrm{T}_{\text {in }}=23.6^{\circ} \mathrm{C}, \\
& -\mathrm{Hr}_{\text {in }}=76.1 \%, \\
& -\mathrm{Habs}_{\text {in }}=13.4 \mathrm{~g} / \mathrm{kg} .
\end{aligned}
$$

The response of the system to the imposed inlet conditions, namely the distributions of the bed temperatures and relative humidity during the adsorption mechanism is illustrated in the following Fig.

Due to the high rate of adsorption, the heat generation rate results in a rapid increase in the bed temperature which rapidly reaches a maximum value $\mathrm{T}_{0}=49.2{ }^{\circ} \mathrm{C}$ and then gradually decreases as the adsorption rate decreases.

Simultaneously, the outlet humidity drop to a minimum, $25.7 \%$ as for the relative humidity and 9.5 $\mathrm{g} / \mathrm{kg}$ for the absolute humidity and then rise toward the inlet values. At saturation, the adsorption process is stopped and the different parameters join the imposed values at the entrance.

Table 1 summarizes the relevant parameters of the test and establishes a comparative study between the inlet and outlet values.

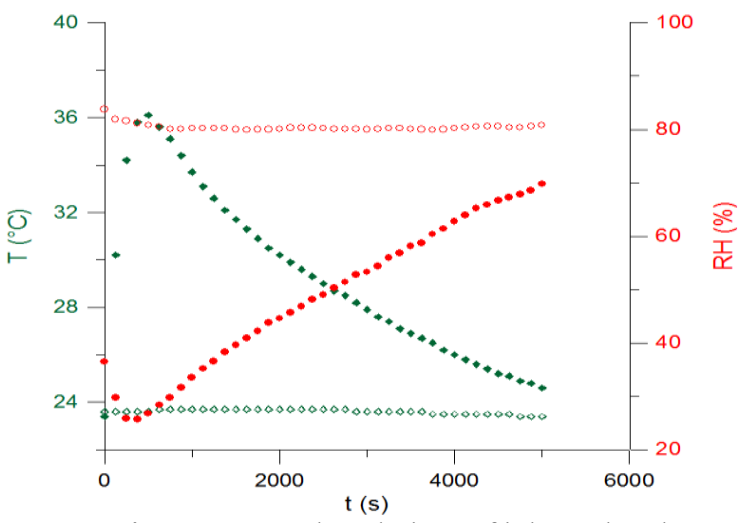

Fig. 4. Temporal evolutions of inlet and outlet temperature and relative humidities.

Table 1. Comparative study between inlet and outlet parameters.

\begin{tabular}{|c|c|c|c|}
\hline $\begin{array}{c}\text { Parameter } \\
\text { characteristics }\end{array}$ & $\begin{array}{c}\text { Air } \\
\text { conditioning } \\
\text { phase }\end{array}$ & $\begin{array}{c}\text { Adsorption } \\
\text { phase peaks }\end{array}$ & $|\Delta \mathbf{V}|$ \\
\hline $\mathrm{T}\left({ }^{\circ} \mathrm{C}\right)$ & 23.6 & 36 & 12.4 \\
\hline $\mathrm{Hr}(\%)$ & 76.1 & 25.7 & 50.4 \\
\hline & & & \\
\hline $\mathrm{Habs}(\mathrm{g} / \mathrm{kg})$ & 13.4 & 9.5 & 3.9 \\
\hline
\end{tabular}

The effect of inlet absolute humidity, fixed and driven at the upstream of the porous bed $\left(\mathrm{w}_{1 \text { in }}=13 \mathrm{~g} / \mathrm{kg}, \mathrm{w}_{2 \text { in }}=\right.$ $17.6 \mathrm{~g} / \mathrm{kg}$ and $\mathrm{w}_{3 \mathrm{in}}=22.2 \mathrm{~g} / \mathrm{kg}$ ), on the adsorption rate is illustrated in Fig. 5. The transient variation of the difference between the absolute humidity measured at the bed exit and that imposed at the inlet is presented for air velocity of $1 \mathrm{~m} / \mathrm{s}$, a bed thickness of $3 \mathrm{~cm}$ and a bed temperature of $31.5^{\circ} \mathrm{C}$. It may be observed that the gap between inlet and exit humidity increases with the increase of inlet humidity. Thus, the hydrophilic character of silica gel is more considerable for higher concentrations of water vapor. This is explicitly illustrated in table 2 which is devoted to recapitulate the different results at the different inlet conditions. Such results may indicate that the desiccant cooling systems are valuable for even large ranges of humid climates.

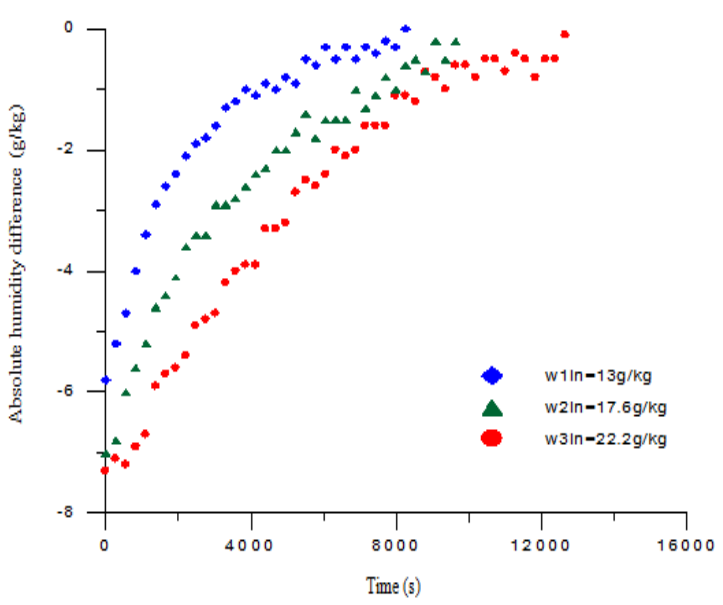

Fig. 5. Transient variation of the absolute humidity difference.

Table 2. Absolute humidity variations with inlet absolute humidity.

\begin{tabular}{|c|c|c|c|}
\cline { 2 - 4 } \multicolumn{1}{c|}{} & Habsin & Habs $_{\mathbf{o}}$ & $\Delta \boldsymbol{H a b s}$ \\
\hline 1 & 13 & 7.2 & 5.8 \\
\hline 2 & 17.6 & 10.6 & 7 \\
\hline 3 & 22.2 & 14.9 & 7.3 \\
\hline
\end{tabular}

Then, the hydrophilic character of silica gel is more considerable for higher concentrations of water vapor.

The effect of phase change material is analyzed. During the experiment climatic conditions were kept constant as those driven with pure silica gel desiccant bed purely.

Thus, the fact of decreasing the inlet air temperature may provide significant enhancement of the bed performance. 
Table 3. Desiccant bed performance with pure silica gel and PCM bed.

\begin{tabular}{|c|c|c|c|c|c|}
\hline $\begin{array}{c}\text { Characte } \\
\text {-ristics }\end{array}$ & ACP & $\begin{array}{c}\text { Pure } \\
\text { SG }\end{array}$ & $|\Delta \mathbf{V}|$ & $\begin{array}{c}\text { PCM } \\
\text { peaks }\end{array}$ & $\begin{array}{c}|\Delta \mathbf{V}| \\
\text { Silica } \\
\text { with } \\
\text { PCM }\end{array}$ \\
\hline $\mathrm{T}\left({ }^{\circ} \mathrm{C}\right)$ & 23.6 & 36 & 12.4 & 28.9 & 5.3 \\
\hline $\mathrm{Hr}(\%)$ & 76.1 & 25.7 & 50.4 & 27.2 & 48.9 \\
\hline $\begin{array}{c}\mathrm{Habs} \\
(\mathrm{g} / \mathrm{kg})\end{array}$ & 13.4 & 9.5 & 3.9 & 6.7 & 6.7 \\
\hline
\end{tabular}

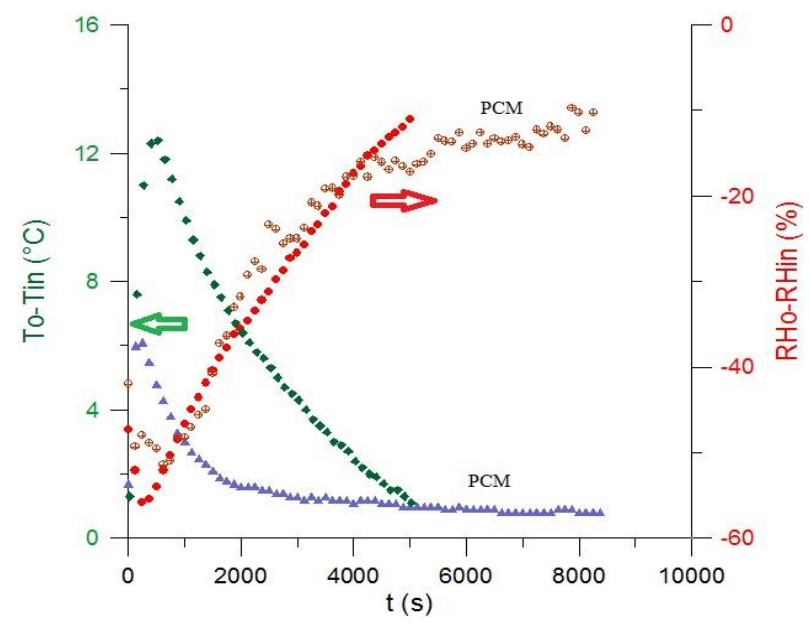

Fig. 6. Temporal influence of phase change material vs pure silica gel bed.

Dehumidification with PCM desiccant bed shows greater moisture removal capacity as the heat generated is lower. The adsorption MRC reaches $50 \%$ and $29 \%$ for maximum temperature difference increase of $12.4{ }^{\circ} \mathrm{C}$ and $5.3^{\circ} \mathrm{C}$, respectively.

\section{Conclusion}

The main results are:

- The gap between inlet and exit humidity increases with the increase of inlet humidity. Such result may indicate that the desiccant cooling systems are valuable for even large ranges of humid climates. Thus, the dessiccant cooling systems are feasible solutions for Mediterranean climates.

- The bed performance is improved for decreasing values of adsorbent temperature which confirms the importance of latent and sensible heat storage particles introduced in the desiccant beds.

\section{References}

1. M. Bakass, H. Bahaj, R. Benaddi and C. Bayane, J. Therm. Anal. Calorim. (2011).

2. J. Hirunlabh, R. Charoenenwat, J. Khedari and S.Teekasap, Build. Env. 42, 572 (2007).

3. D.G. Waugaman, A. Kini, C.F. Kettleborough, J. Energy Res. Tech. 115, 1.
4. D. M. Ruthven, New York, 5, (1994).

5. C. M. Shen and W. M. Worek, Int. J. Heat Mass Transfer, 37(14) 2123, (1994).

6. Y. Saito, J. Solar Energy Engng. , 115, 169, (1993).

7. K. Matsuki and Y. Saito, Desiccant cooling R\&D in Japan, ASHRAE, DA-88-1-2:537-51, (1988).

8. M. Dupont, B. Celestine, P. H. Nguyen, J. Merigoux, B. Brandon,J. Solar Energy, 52, 519, (1994).

9. M. Ito. T. Asano, M. Hasatani and F. Watanabe, Fifth Workshop, Final Proceedings Tsu, Japan, 1214 April, (2000).

10. J. Y. San and G. D. Jiang, Int. Heat Mass Transfer, 37, 1173, (1994). 